\title{
Notes on the vocalizations of Buffy Tuftedcheek (Pseudocolaptes lawrencii)
}

Peter Boesman

In the following we briefly analyze and compare voice of the different races of Buffy Tuftedcheek (Pseudocolaptes lawrencii). We also try to quantify the extent of any vocal differences using the criteria proposed by Tobias et al. (2010), as a support for taxonomic review. We have made use of sound recordings available on-line from Xeno Canto (XC) and Macaulay Library (ML).

Song of the 2 races, johnsoni ('Pacific Tuftedcheek') and lawrencii, seems to be quite different.

\section{johnsoni}

Song is a high-pitched rattled series of notes slowing into stuttering and ending (always) with a characteristic high-pitched downslurred note (overall not unlike a chasing call of some Hummingbirds, but obviously more powerful). Sometimes preceded by loud call notes, not clear if these are part of the full song (Fig. 1).
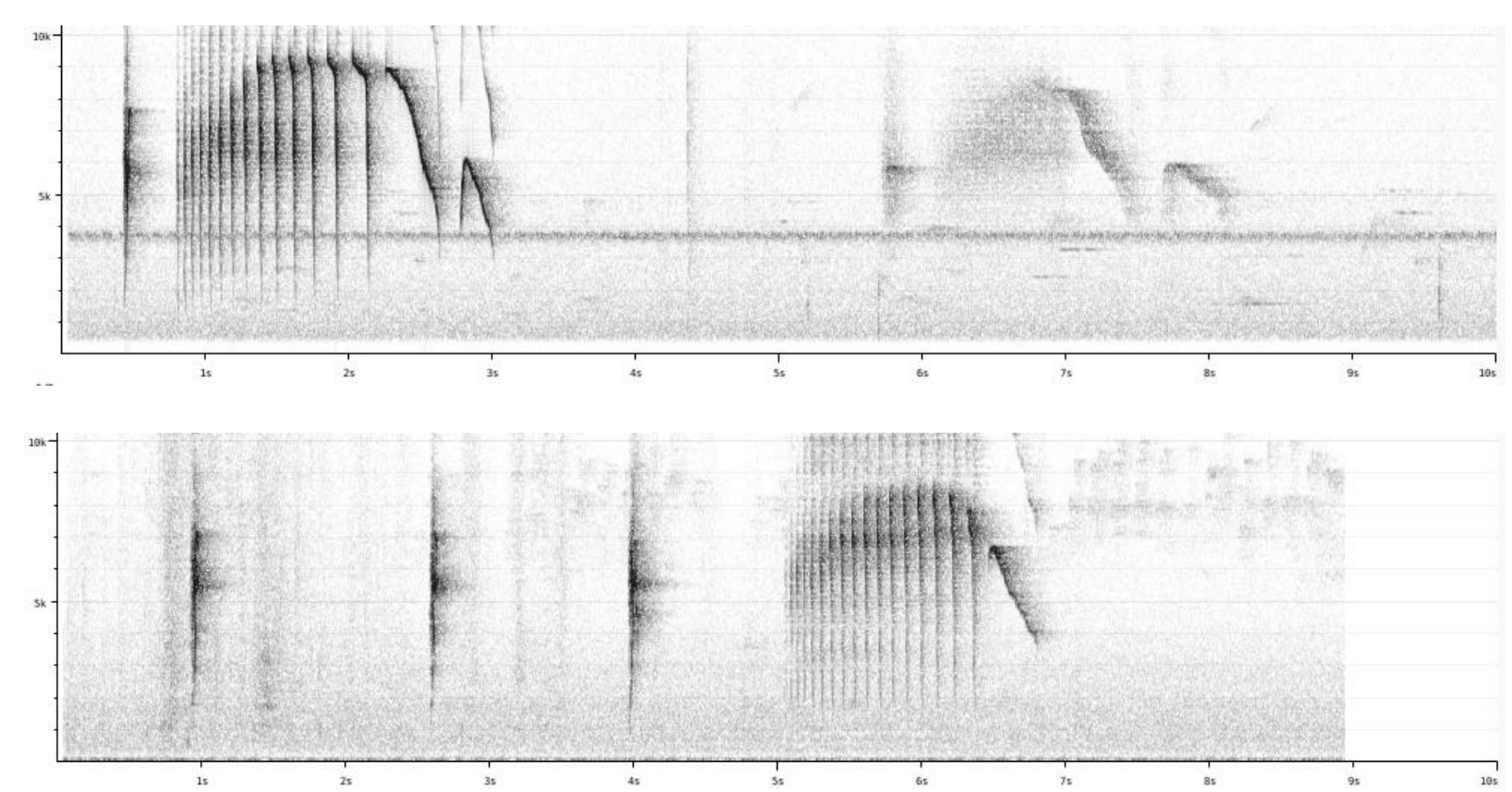

Figure 1: typical song of johnsoni from Colombia (top) and Ecuador (bottom) 

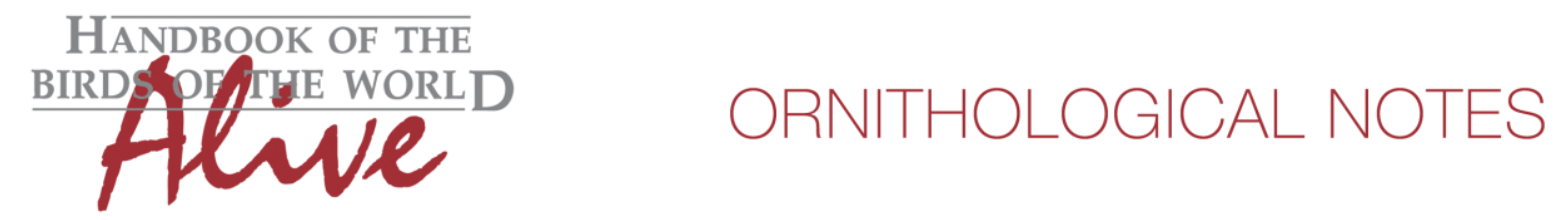

\section{lawrencii}

Song is a number of well-spaced staccato notes (always present unlike johnsoni) followed by a trill, which usually first ascends in pitch and then slightly descends while slowing down in pace (Fig. 2). (A note of caution: this description is only based on 1 recording from Panama and 3 (of the same bird) from Costa Rica. Voice is however also described in Stiles and Skutch (1989), a reliable source for voice descriptions, and confirms the recordings)

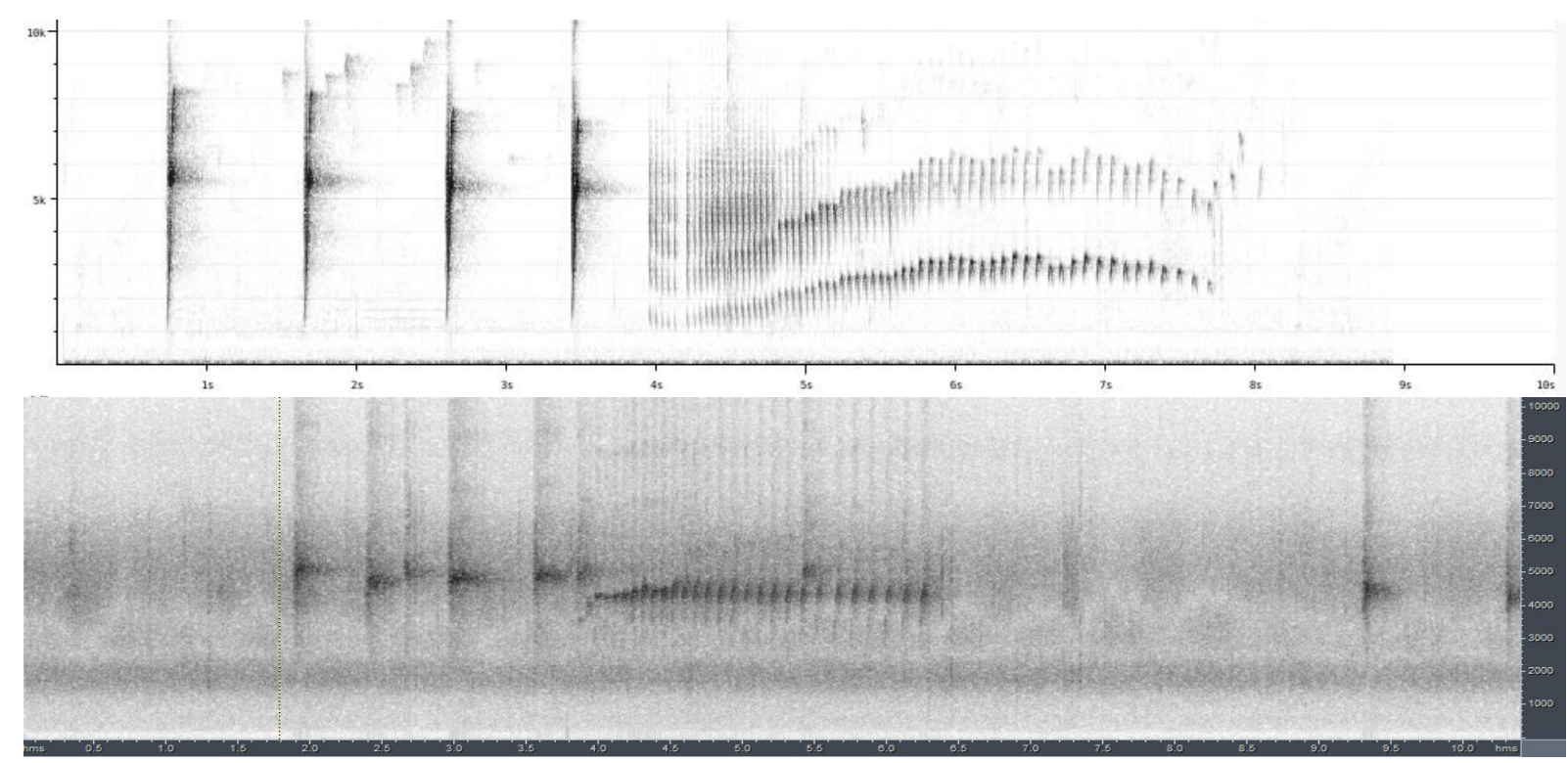

Figure 2: typical song of lawrencii from Costa Rica (top) and Panama (bottom)

There seems to be quite some variation in voice, especially when birds are excited (e.g. playback). johnsoni also utters a rattle which comes closer to lawrencii, but this doesn't seem to be the primary song.

Measurement of basic parameters of trilled part:

\section{johnsoni $(n=7)$}

max. frequency

note length at start

pace at start (over 5)

note length towards end

pace towards end

length downward slur

number of introductory notes

note shape

lawrencii $(n=4)$

max. frequency

note length at start

pace at start (over 5)

note length towards end

pace towards end

length downward slur

number of introductory notes

note shape

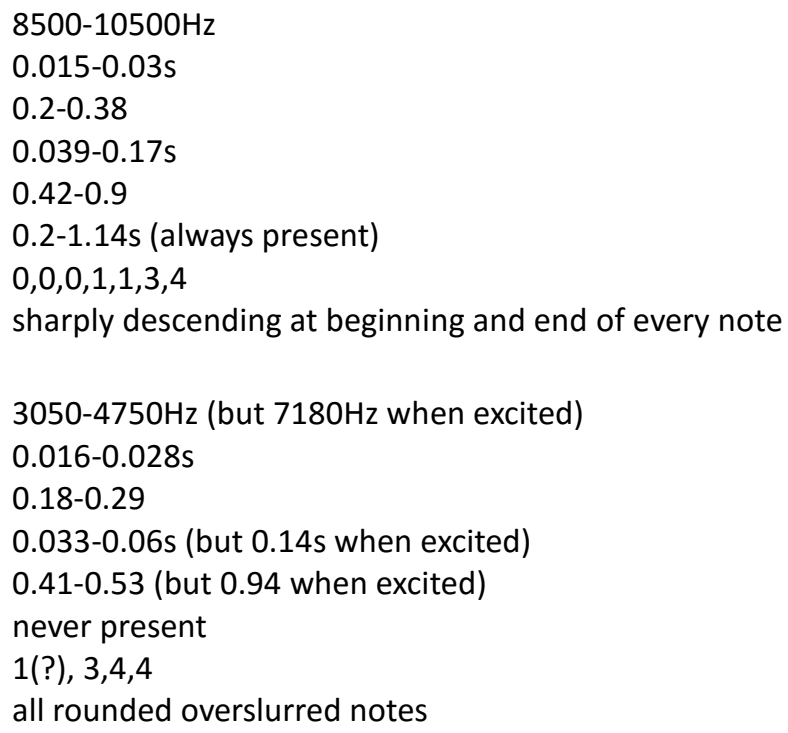



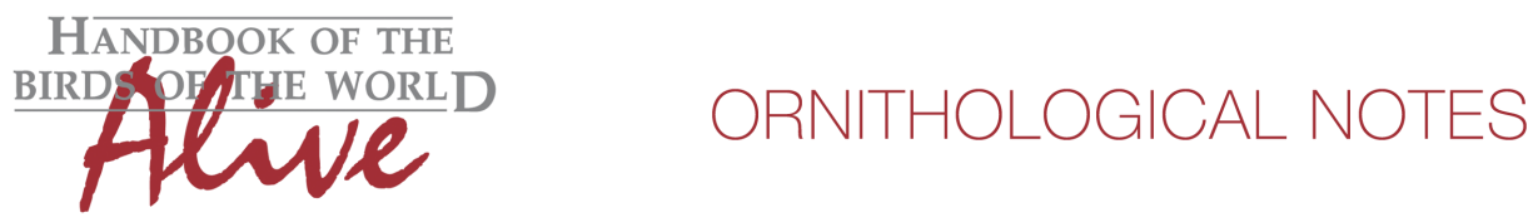

Assuming the few recordings of lawrencii are typical for the song of this race, we can conclude the following:

Song of 'Pacific Tuftedcheek' johnsoni differs mainly from lawrencii by its much higher frequency (score 2), the presence of a long down-slurred ending note (score 2) and different shape of notes (score 1). This would lead to a total vocal score of 4 by applying Tobias criteria.

This note was finalized on 17th April 2015, using sound recordings available on-line at that moment. We would like to thank in particular the sound recordists: Andrew Spencer (with 3 of the 4 recordings of lawrencii) and Dodge Engleman (whose recording was published in Boesman 2011), and for johnsoni Nick Athanas, Olaf Jahn, Niels Krabbe, Mitch Leisinger, Oscar Marín Gomez, Manuel Sanchez, Andrew Spencer, Charlie Vogt and Julian Zuleta Marín.

\section{References}

Boesman, P. (2011). Birds of Costa Rica - MP3 sound collection. MP3-DVD. Belgium.

Stiles, F.G. \& Skutch, A.F. (1989). A Guide to the Birds of Costa Rica. Christopher Helm, London.

Tobias, J.A., Seddon, N., Spottiswoode, C.N., Pilgrim, J.D., Fishpool, L.D.C. \& Collar, N.J. (2010). Quantitative criteria for species delimitation. Ibis 152(4): 724-746.

\section{Recommended citation}

Boesman, P. (2016). Notes on the vocalizations of Buffy Tuftedcheek (Pseudocolaptes lawrencii). HBW Alive Ornithological Note 87. In: Handbook of the Birds of the World Alive. Lynx Edicions, Barcelona. (retrieved from http://www.hbw.com/node/931981 on 18 July 2016). 